\title{
Severe sepsis caused by a gas-forming Clostridium perfringens and Klebsiella variicola liver abscess following total pancreatectomy
}

\author{
Stig Søgaard Dahl, ${ }^{1}$ Morten Thorsteinsson, ${ }^{1}$ Trine-Lise Lambine, ${ }^{2}$ Luit Penninga ${ }^{1}$
}

'Department of Surgery and Transplantation, Rigshospitalet, Copenhagen University Hospital, Copenhagen, Denmark ²Department of Radiology, Rigshospitalet, Copenhagen University Hospital, Copenhagen, Denmark

Correspondence to Dr Luit Penninga; LP@ctu.dk

Accepted 23 September 2020

\section{DESCRIPTION}

A 68-year-old man, with a history of hypertension and smoking, had undergone a total pancreatectomy due to pancreatic cancer, without major complications.

One month after the operation, prior to adjuvant chemotherapy, the patient was admitted to the local hospital with fever $\left(39.2^{\circ} \mathrm{C}\right)$ and abdominal pain (Visual Analog Scale (VAS): 5). Laboratory testing showed a C-reactive protein of $68 \mathrm{mg} / \mathrm{L}$ and the leucocyte count was $24.9 \times 10^{9} / \mathrm{L}$. The patient was started on intravenous piperacillin-tazobactam and metronidazole. An acute CT of the abdomen revealed a hyperdense area in the sixth liver segment, suspicious of an abscess. Within 6 hours of arrival, the condition of the patient deteriorated rapidly, and he was transferred to the local intensive care unit (ICU) with severe septic shock (quick Sequential Organ Failure Asessment score (qSOFA-score): 3), acute anaemia (haemoglobin $3.7 \mathrm{mmol} / \mathrm{L}$ ) and acute renal and hepatic failure. Following initial stabilisation, a CT angiography was performed which showed gas formation in the previous hyperdense area (figure 1). The blood culture taken on arrival showed growth with Clostridium perfringens and a small number of Klebsiella variicola. The patient was transferred to the ICU of our hospital and meropenem and ciprofloxacin was added to the antibiotic treatment. An ultrasonically guided drain was placed in the abscess within $45 \mathrm{~min}$ of arrival (figure 2). The abscess was drained for air and $400 \mathrm{~mL}$ pus. Subsequent cultures from the abscess confirmed the blood culture with growth of $C$. perfringens and $K$. variicola. Hereafter, the patient stayed in the ICU for 9 days undergoing hyperbaric oxygen treatment and continuous renal replacement therapy. Most of the blood samples were later withdrawn due to spectrophotometric interference caused by disseminated intravascular coagulation (DIC). The patient was treated for an additional 12 days before being discharged to the local hospital, where he continued intermittent dialysis treatments.

C. perfringens is the bacteria known to cause gas gangrene, a dangerous skin infection with rapid toxin-mediated tissue gas development followed by necrosis. ${ }^{1}$ It is an anaerobic Gram-positive rodshaped bacterium found naturally in dirt samples and in the intestinal tract of humans.

$K$. variicola is a relatively newly discovered bacterium first described in $2004 .^{2}$ It is a Gram-negative, non-motile, rod-shaped bacterium found in

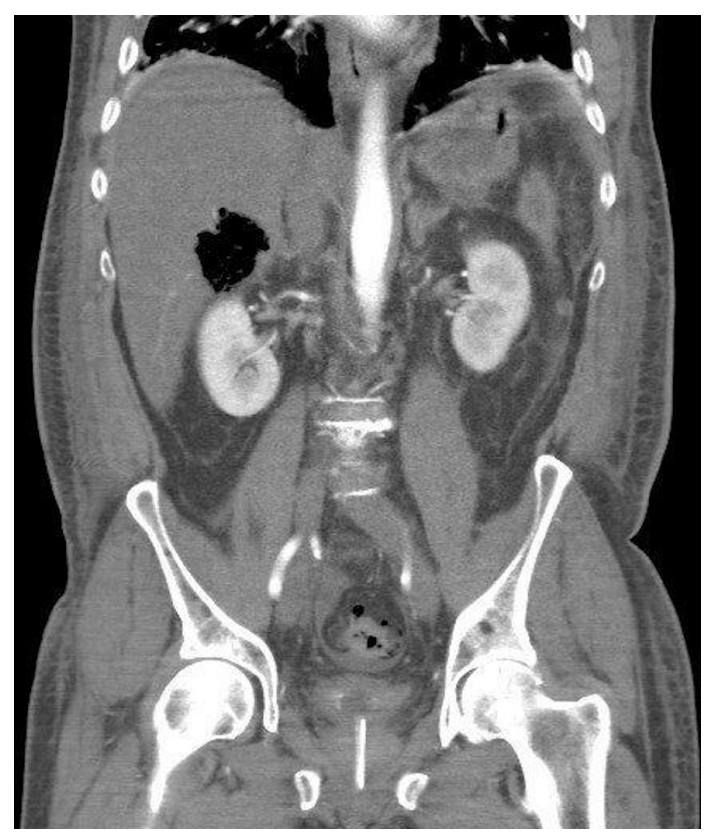

Figure 1 CT 24 hours after hospitalisation showing gas formation in the liver abscess.

different plants. ${ }^{2}$ Due to its new discovery and close resemblance to Klebsiella pneumonia, it is often misclassified as K. pneumonia. ${ }^{3}$ Being non-motile the bacteria is extremely rare in liver abscesses. To our knowledge, this is the first described case.

Total pancreatectomy is a specialised procedure where the entire pancreas, spleen, duodenum, gall bladder and common hepatic duct are removed, and reconstruction with a hepaticojejunostomy and a gastrojejunal anastomosis is performed.

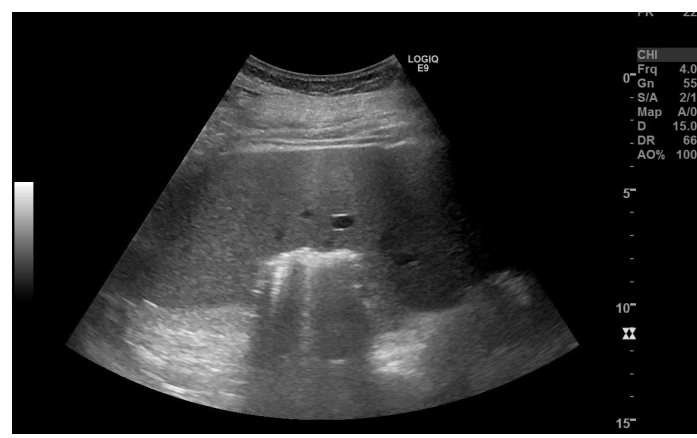

Figure 2 Ultrasound showing liver abscess containing gas and pus. A drain was subsequently placed ultrasoundguided in the abscess cavity. 
Manifest malnutrition requiring enzyme supplements and insulin-dependent diabetes mellitus is a certain outcome. In this case, a robot-assisted distal pancreatectomy was intended and performed, intraoperative frozen section pathology from the resected surface returned with adenocarcinoma twice. Hence, the procedure was converted to an open surgery total pancreatectomy. Common complications of a total pancreatectomy include haemorrhage, leakage from the hepaticojejunostomy and postoperative infection.

Liver abscess with $C$. perfringens is a very rare but very severe complication, which has only been reported in a very limited number of cases. ${ }^{145}$ The condition was associated with a $70 \%$ risk of death. ${ }^{6}$ Interestingly, the abscesses usually present after infection or surgery involving the bile system. ${ }^{5}$ Known risk factors are diabetes, cancer immunosuppression or a combination. Once

Learning points

Liver abscess caused by Clostridium perfringens is a rare but very serious complication to infection and surgery involving the bile system that causes severe sepsis, haemolysis and multiorgan failure.

- Rapid evacuation of the abscess and treatment of complications to septic shock seem to be essential factors in patient outcome.

- Treatment with antitoxin can be considered, bacteriostatic treatment may theoretically be preferred to bactericide antibiotic. the alpha-toxin has been released septic shock and DIC evolve extremely fast. Time-to-intervention is consistently an important factor in the surviving cases.

The use of bactericide antibiotic might inadvertently cause the release of the toxin from inside the bacteria. Treatment with toxin-antidote has been suggested, but has not been properly tested in humans for this indication.?

Contributors SSD, MT and LP had the idea of the study. SSD prepared the manuscript. SSD, MT, T-LL and LP critically revised the manuscript. All authors accepted the final version of the manuscript.

Funding The authors have not declared a specific grant for this research from any funding agency in the public, commercial or not-for-profit sectors.

Competing interests None declared.

Patient consent for publication Obtained.

Provenance and peer review Not commissioned; externally peer reviewed.

\section{REFERENCES}

1 Paasch C, Wilczek S, Strik MW. Liver abscess and sepsis caused by Clostridium perfringens and Klebsiella oxytoca. Int J Surg Case Rep 2017;41:180-3.

2 Rosenblueth M, Martínez L, Silva J, et al. Klebsiella variicola, a novel species with clinical and plant-associated isolates. Syst App/ Microbiol 2004;27:27-35.

3 Rodríguez-Medina N, Barrios-Camacho H, Duran-Bedolla J, et al. Klebsiella variicola: an emerging pathogen in humans. Emerg Microbes Infect 2019;8:973-88.

4 Vuolio S, Vähäkari M, Laurila J, et al. Liver abscess and sepsis caused by Clostridium perfringens. Duodecim 2016;132:1904-7.

5 Tabarelli W, Bonatti $\mathrm{H}$, Cejna M, et al. Clostridium perfringens liver abscess after pancreatic resection. Surg Infect 2009;10:159-62.

6 Law S-T, Lee MK. A middle-aged lady with a pyogenic liver abscess caused by Clostridium perfringens. World J Hepatol 2012;4:252-5.

7 Hifumi T, Koido Y, Takahashi M, et al. Antitoxin treatment for liver abscess caused by Clostridium perfringens. Clin Mol Hepatol 2013;19:97-8.

Copyright 2020 BMJ Publishing Group. All rights reserved. For permission to reuse any of this content visit

https://www.bmj.com/company/products-services/rights-and-licensing/permissions/

BMJ Case Report Fellows may re-use this article for personal use and teaching without any further permission.

Become a Fellow of BMJ Case Reports today and you can:

- Submit as many cases as you like

- Enjoy fast sympathetic peer review and rapid publication of accepted articles

- Access all the published articles

Re-use any of the published material for personal use and teaching without further permission

Customer Service

If you have any further queries about your subscription, please contact our customer services team on +44 (0) 2071111105 or via email at support@bmj.com.

Visit casereports.bmj.com for more articles like this and to become a Fellow 